\title{
Study on wellbore instability mechanism and drilling fluid optimization of Yingsha block in southwest Tarim Basin
}

\author{
Yong Sheng ${ }^{1}$, Yan Ye ${ }^{2,3, *}$, Zhishi Zhou ${ }^{1}$, Guangxu Zhou ${ }^{2,3}$, Wei Luo ${ }^{1}$, Lingling Ren ${ }^{1}$, and Hanxuan Song ${ }^{2,3}$ \\ ${ }^{1}$ PetroChina Tarim Oilfield Company, 841000 Xinjiang, China \\ ${ }^{2}$ School of Petroleum Engineering, China University of Petroleum, 102249 Beijing, China \\ ${ }^{3}$ State Key Laboratory of Petroleum Resource and Prospecting China University of Petroleum Beijing, China
}

\begin{abstract}
The southwest area of Tarim has good potential for exploration and development, but the geological conditions of Yingsha block are complicated and complex conditions occurred frequently in drilling operations. There were 11 times lost circulation, which ranged from $\mathrm{N}_{2} a$ to $\mathrm{E}_{1} a$ and the lithology ranged from mudstone and sand-mudstone interbeds to gypsum rock, and the drilling cycle is up to 719 days, which seriously restricts the exploration and development of oil and gas resources. In this paper, the rock mineral composition and physical and chemical characteristic profiles of the whole well have been established for the well drilled in this area. The characteristic profiles show that quartz $(21.4 \% \sim 57.4 \%)$ and clay minerals $(17 \% \sim 44.9 \%)$ are the main layers in the lower strata $(5069 \mathrm{~m}-7015 \mathrm{~m})$ drilled in Yingsha. The clay minerals are dominated by illite $(58 \% \sim 85.75 \%)$ without smectite. The highest proportion of illite/smectite formation is $25 \%$, the highest expansion rate is $23.87 \%$, and the lowest recovery rate is $3 \%$. Therefore, the stratum has strong hydration and dispersion characteristics. The average porosity of $4064 \mathrm{~m}-$ $6666.5 \mathrm{~m}$ is $1.86 \%-6 \%$, and the formation cracks are well developed. The wellbore instability mechanism in Yingsha is the good physical property of the sandstone, the development of cracks and micro-cracks in the lower strata, the broken strata, and the strong hydration and dispersion ability. The performance evaluation of KCL-Polysulfonate drilling fluid used in Yingsha shows that the recovery rate increases to more than $80 \%$ when the amount of KCL is $7-10 \%$. With the introduction of paraffin nano-emulsion, the filtration loss is reduced by $30 \%$, and the inhibition and plugging performance of drilling fluid is further improved.
\end{abstract}

\section{Introduction}

Tarim basin is the largest petroliferous basin on land in China, with abundant hydrocarbon resources. The oil and gas reservoirs in Tarim Basin are generally ultradeep and the geological structure is highly complex. The total proven oil and gas resources are $178 \times 10^{8} \mathrm{t}$, including $75 \times 10^{8} \mathrm{t}$ of oil and $12.9 \times 10^{12} \mathrm{~m}^{3}$ of natural gas, which is one of the basins with the greatest exploration difficulty and potential in China. The southwest area of Tarim Basin has great exploration potential and is an important oil and gas exploration zone in Tarim Basin [1-8]. The Southwest depression is located in the southwest of Tarim Basin, adjacent to the western segment of South Tianshan fold belt and Bachu uplift in the north, west Kunlun mountain fold belt in the southwest, and Tanggu depression in the east. It mainly includes the West Kunlun mountain piedmont thrust belt, south Tianshan piedmont thrust belt, Kashgar sag, Yecheng-Hotan sag, and Maigaiti slope. Yingjisha structural belt is located in the front of Sugait-Qimugen structural section, and Yingsha block is also located in Yingjisha structural belt. Stratigraphic conditions in Yingsha block are complicated, and complex well conditions such as lost circulation, overflow and sticking of drill tools generally occur during drilling, which restricts the efficient development of oil and gas resources. The instability of wellbore and the occurrence of complex well conditions are the difficulties in the development process of this area.

\section{Analysis of drilling complex accident}

YSE-1 well in Yingsha block was the first completed drilling in 2005, with a depth of $7258 \mathrm{~m}$. See Figure 1 for the statistics of the complex well conditions and well body structure. As can be seen from Fig. 1, the complex condition of this well is dominated by lost circulation and sticking of drill tools. The complex upper strata are concentrated in Atushi Formation, and there are lost circulation and overflow caused by multiple pressure systems and cracks in this formation. There are lost circulation in the lower strata, mainly due to the good physical properties of sandstone and the existence of cracks in the strata, including Keziluoyi Formation, Bashibulake Formation and Qimugen Formation.

* Corresponding author: yeyan@cup.edu.cn 


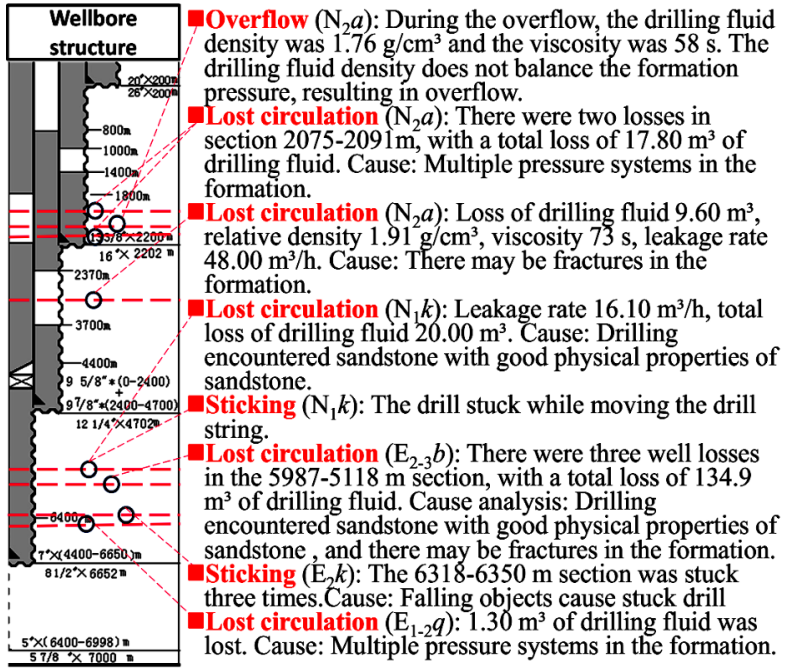

Fig. 1. Complex well conditions of YSE-1 well.

In recent years, in order to improve the exploration efforts in the southwest area of Tarim Basin, YSA-1 well was drilled in Yingsha area in 2019 with a drilling depth of $7015 \mathrm{~m}$. See Figure 2 for the statistics of the complex well conditions and wellbore structure. As can be seen from Fig. 2, there are lost circulation, sticking of drill tools and overflow in the $\mathrm{E}_{1} a$ of the lower strata. The main reason is that drilling into the high-pressure salt water layer caused the overflow and in the process of handling the overflow, differential pressure sticking and high drilling fluid density resulted in lost circulation and return loss.

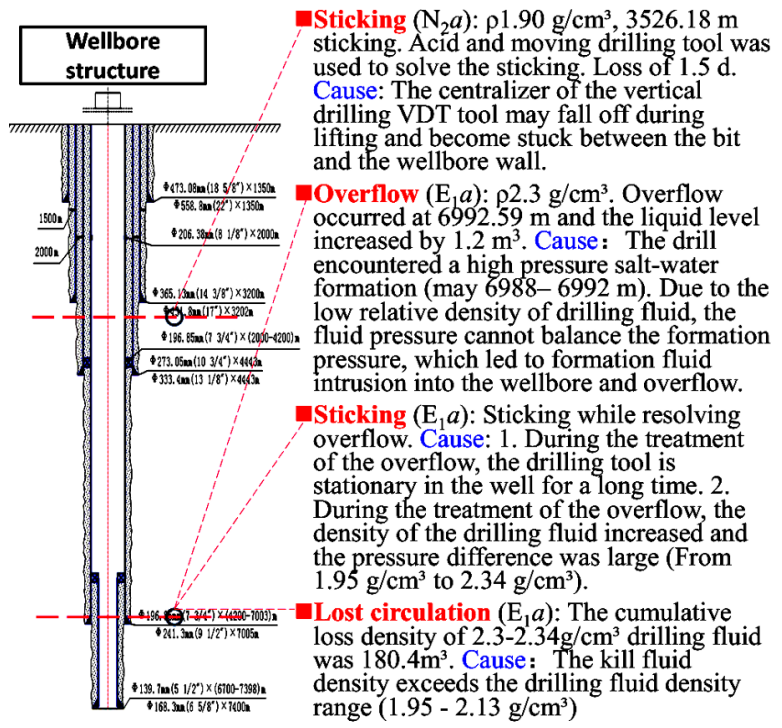

Fig. 2. Complex well conditions of YSA-1 well.

Combined with other Wells drilled in Yingsha block, complex well conditions in this area mainly occur in the Atushi Formation in the upper strata, while in the lower strata, they occur in the Keziluoyi Formation, Bashibulake Formation, Alataer Formation, Qimugen Formation and Aertash Formation. The complex well conditions mainly include lost circulation and sticking of drill tools. In some sections of the Atushi Formation, there are multiple pressure systems in the formation that cause lost circulation. In other stratum, the lost circulation is mainly caused by the development of fractures or the sandstone with good physical properties. Causes of sticking include poor drilling fluid performance, high viscosity, delayed drilling tool movement, differential pressure sticking, and hard falling material sticking.

There are few well drilled data in Yingsha block, so it is necessary to analyse the formation composition and physical and chemical characteristics of this block, and give a more comprehensive understanding of the cause of wellbore instability in Yingsha block.

\section{Stratigraphic composition and characteristic analysis of Yingsha block}

\subsection{Crack and microstructure analysis}

The crack development of Yingsha block was sorted out, and the results are shown in Table 1. The formation cracks developed in this block, and the average porosity is between $1.86 \%$ and $6 \%$. The existence of cracks in the lower strata is an important reason for the occurrence of lost circulation in Yingsha block.

Table 1. Porosity statistics.

\begin{tabular}{|c|c|c|c|}
\hline \multirow{2}{*}{ well } & $\begin{array}{c}\text { well section } \\
(\mathrm{m})\end{array}$ & $\begin{array}{c}\text { Porosity } \\
\text { range }\end{array}$ & $\begin{array}{c}\text { Average } \\
\text { porosity }\end{array}$ \\
\hline \multirow{3}{*}{ YSE-1 } & $5668-5866$ & $1-7.9 \%$ & $3.26 \%$ \\
\cline { 2 - 4 } & $6272-6399$ & $0.1-7.2 \%$ & $1.88 \%$ \\
\hline \multirow{4}{*}{ YK-1 } & $4064-4539$ & $0.6-6.5 \%$ & $3.70 \%$ \\
\cline { 2 - 4 } & $5355-5779$ & $1.1-5.6 \%$ & $3.27 \%$ \\
\cline { 2 - 4 } & $6104-6290$ & $4-15 \%$ & $5.41 \%$ \\
\hline \multirow{4}{*}{ YSA-1 } & $4449-5018$ & $0.6-11.3 \%$ & $6.00 \%$ \\
\cline { 2 - 4 } & $5024.5-5600.5$ & $1.1-9.4 \%$ & $4.33 \%$ \\
\cline { 2 - 4 } & $5964-6211$ & $1.1-5.6 \%$ & $2.46 \%$ \\
\cline { 2 - 4 } & $6218-6531.5$ & $0.1-7.1 \%$ & $2.89 \%$ \\
\cline { 2 - 4 } & $6599-6666.5$ & $0.8-4.2 \%$ & $1.86 \%$ \\
\hline
\end{tabular}

\subsection{Analysis of rock and mineral components}

The whole rock compositions and clay mineral compositions were analyzed by X-ray diffraction (XRD) using cuttings samples from the lower formation of YSA-1 well. See Figure 3 and Figure 4 for the well depth profiles of whole rock mineral components and clay minerals established in YSA-1 well. 


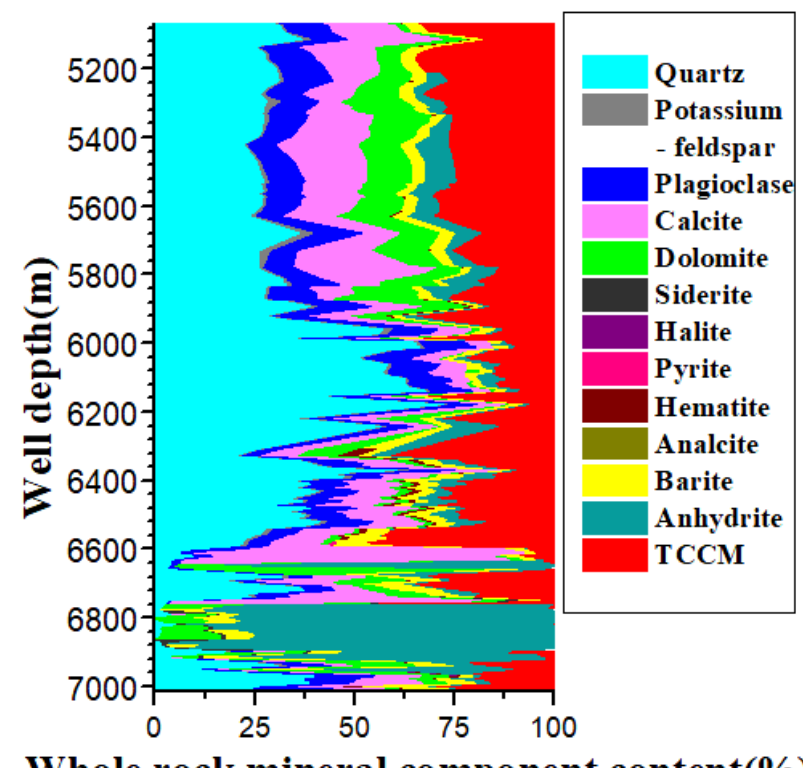

Whole rock mineral component content(\%)

Fig. 3. Whole rock mineral composition profile of YSA-1 well.

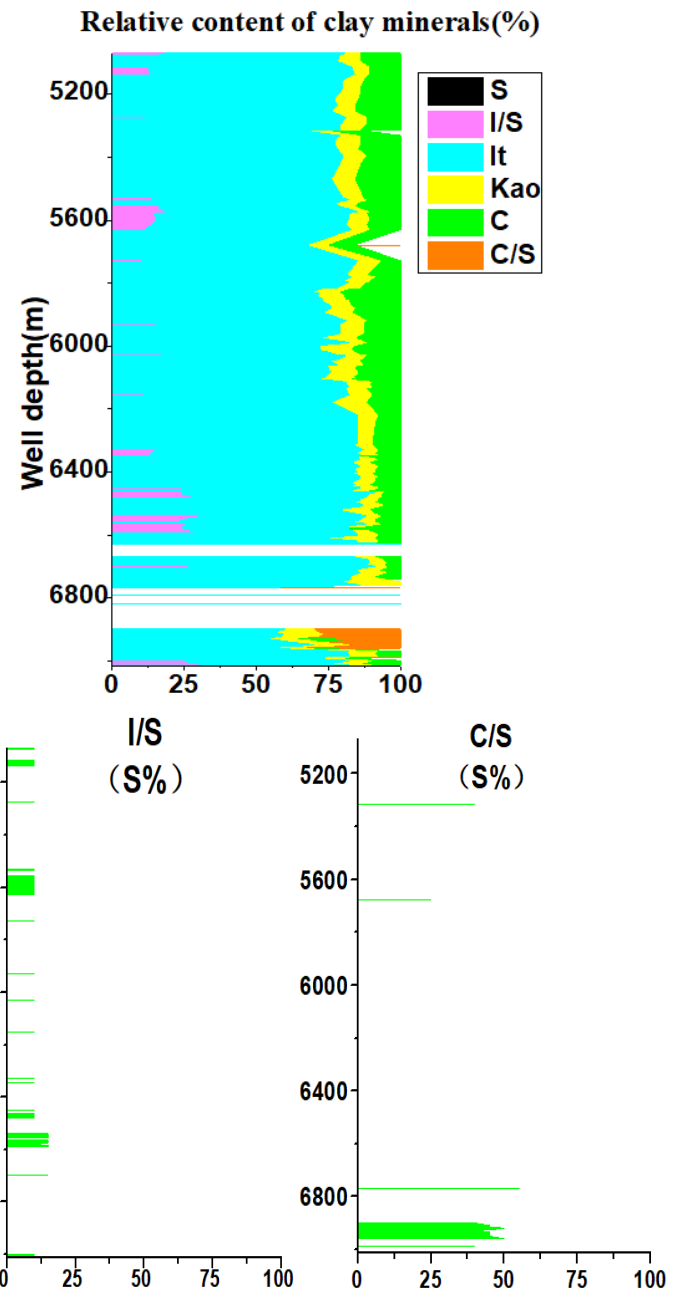

Fig. 4. Clay mineral composition profile of YSA-1 well.

Most of the lower strata in YSA-1 well are dominated by quartz and clay minerals, while feldspar, calcite, dolomite, hematite and so on are developed in different degrees. Quartz content is 5.2\% 57.4\% and clay minerals content is $4.9 \% \sim 44.9 \%$ in different formations. Kalataer Formation is dominated by calcite
(44.2\%). Atush Formation is dominated by anhydrite $(60.6 \%)$, with almost no clay minerals. There is no smectite in each formation, but illite is the main one, accounting for $58 \% \sim 85.75 \%$ on average. The Kalataer Formation and Aertash Formation do not contain illite/smectite formation, and the other formations have the largest proportion of illite/smectite formation of $25 \%$, which is easy to cause hydration expansion and thus lead to wellbore instability.

\subsection{Analysis of rock mechanical properties}

Due to the limitation of difficult core-taking during drilling, the number of cores in this block is small. The mechanical properties of rock are analyzed by using logging data. Through Visual Basic programming, according to well depth, compressional wave time difference, density, natural gamma ray and other data in logging data, the profile of rock mechanics parameters is shown in Figure 5.
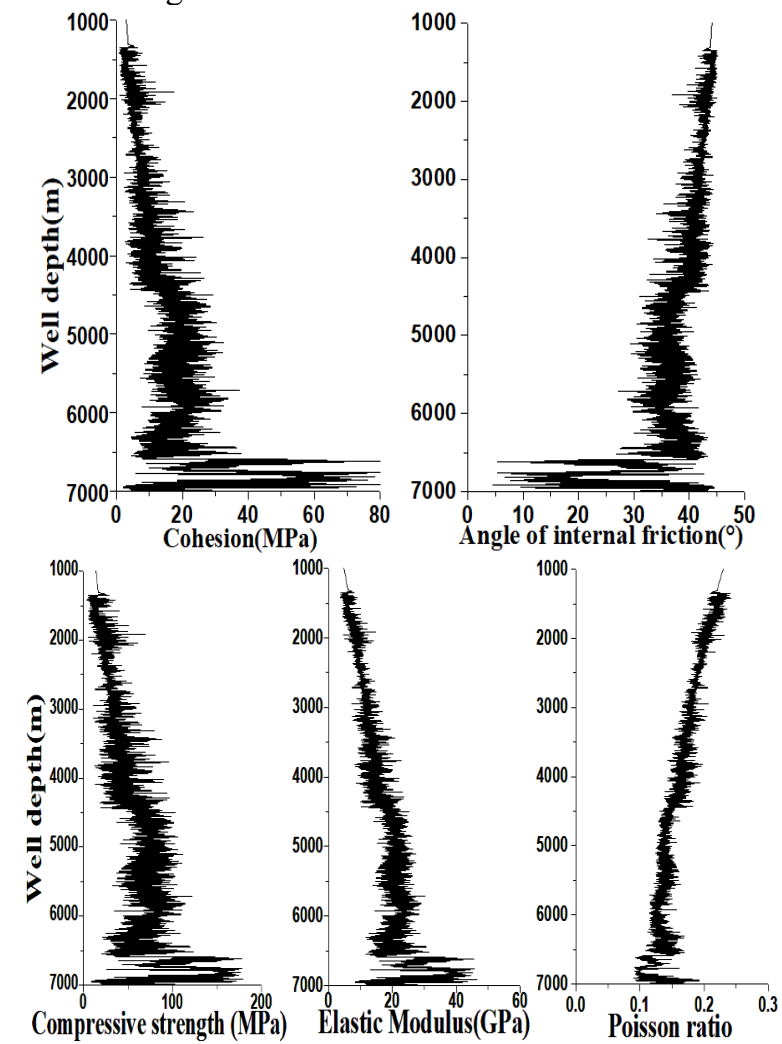

Fig. 5. Rock mechanics parameters profile of YSA-1 well.

The results show that the rock mechanical parameters of YSA-1 well fluctuate greatly, especially the rock of the lower strata has a strong heterogeneity, and the cohesion and compressive strength vary greatly, so the wellbore instability is easy to occur.

\subsection{The physical and chemical properties}

According to the standard SYT5613-2016, the expansion rate experiment and the water rolling recovery experiment were carried out using the lower formation debris of YSA-1 well, and the expansion rate of YSA-1 well is shown in Figure 6 and the water rolling recovery rate is shown in Figure 7. 


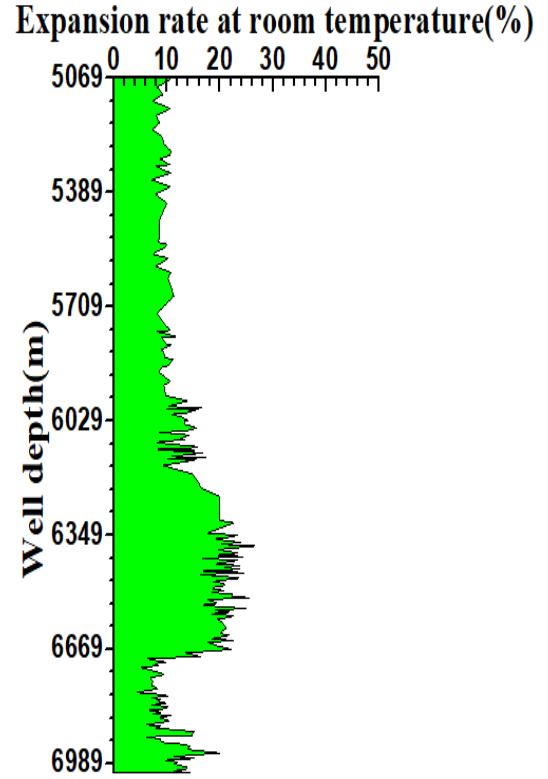

Fig. 6. Expansion rate profile of YSA-1 well.

The expansion rate ranges from $3.73 \%$ to $23.87 \%$, and there is a great difference between different formations. The Aertash Formation is dominated by anhydrite and do not contain clay minerals, so the expansion rate is between $3.73 \%$ to $8.15 \%$. For the stratum containing clay minerals but without mixed formation, the expansion rate is generally about $15 \%$. The Bashibulake Formation, Wulagen Formation, Kalataer Formation and Qimugen Formation have high expansion rate, which are all above $20 \%$, with strong expansibility.

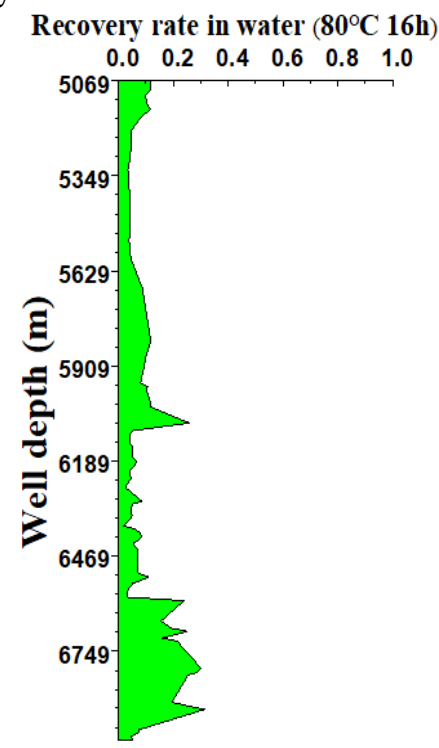

Fig. 7. Recovery rate in water of YSA-1 well.

The water rolling recovery rate range from $3 \%$ to $30 \%$. The central part of Anjuan Formation, the lower part of Keziluoyi Formation and the upper part of Bashibulake Formation are relatively low, which basically range from $2.01 \%$ to $5.37 \%$. On the whole, there is strong hydration swelling in the well sections of Anjuan Formation, Keziluyi Formation, Bashibulake
Formation, Wulagen Formation, Kalataer Formation and Qimugen Formation, which can easily cause wellbore instability.

\section{Mechanism of wellbore instability}

By studying the formation composition, physical and chemical properties, rock mechanical properties, crack development and the complex conditions of drilling in Yingsha block, it is considered that the wellbore instability mechanism in Yingsha block includes three aspects:

(1) The physical properties of sandstone in Yingsha block are good. Meanwhile, fractures and microfractures are developed in the lower strata, and the strata are broken. Therefore, lost circulation is easy to occur and the mechanical strength of rock is affected.

(2) The lower strata have strong expansibility, hydration and dispersion, further weakening the rock strength and leading to fracture propagation.

(3) There are many pressure systems in the formation, and the heterogeneity is strong, which easily leads to the occurrence of wellbore instability.

Considering the good physical properties of sandstone, the development of formation fractures and the occurrence of loss while drilling, particle grading is used to optimize the drilling fluid, and suitable smallsize pore plugging materials are selected to further improve the plugging performance of drilling fluid. For the lower formation with strong hydration and dispersion ability, the inhibition performance of drilling fluid system should be improved to reduce hydration and dispersion.

\section{Performance evaluation of current drilling fluid and optimization study}

\subsection{Performance evaluation of current drilling fluid}

The current drilling fluid used in YSA-1 well is $\mathrm{KCl}$ polysulfone drilling fluid system, which has strong high temperature resistance and salt resistance. At the same time, a high content of $\mathrm{KCl}$ is maintained in the system to improve the inhibition performance of drilling fluid. It is a drilling fluid system with good high temperature resistance, strong inhibition performance, good stability, good lubricity and suitable for drilling in complex formations [9-11]. The drilling fluid obtained from YSA1 well is used for performance test, and the formula is bentonite $4-6 \%+$ caustic soda $0.2-0.5 \%+$ sulfonomethyl phenolac resin $2-5 \%+$ lignite resin $2-5 \%+$ anti-slumping agent $2-5 \%+$ potassium chloride $5-10 \%$ lubricant $3-5 \%+$ weighting agent. The performance of drilling fluid is shown in Table 2. 
Table 2. Current drilling fluid properties of YSA-1 well.

\begin{tabular}{|c|c|c|c|c|c|c|c|}
\hline $\begin{array}{c}\text { Well } \\
\text { depth }(\mathrm{m})\end{array}$ & $\begin{array}{l}\text { Densi-ty } \\
\left(\mathrm{g} / \mathrm{cm}^{3}\right)\end{array}$ & $\begin{array}{c}\text { Apparent } \\
\text { viscosity } \\
(\mathrm{MPa} \cdot \mathrm{s})\end{array}$ & $\begin{array}{c}\text { Plastic } \\
\text { viscosity } \\
(\mathrm{MPa} \cdot \mathrm{s})\end{array}$ & $\begin{array}{c}\text { Yieldi-ng } \\
\text { degree }(\mathrm{pa})\end{array}$ & $\begin{array}{c}\text { Shear-ing } \\
\text { force }(\mathrm{pa})\end{array}$ & $\begin{array}{c}\text { Shea-ring } \\
\text { force } \\
(\mathrm{mm})\end{array}$ & $\begin{array}{c}\text { HTHP water } \\
\text { loss } \\
(\mathrm{mL})\end{array}$ \\
\hline 6320 & 2.0 & 34.5 & 30 & 4.5 & $2.5 / 21$ & 4.5 & 4.8 \\
\hline
\end{tabular}

The drilling fluid is used to carry out rolling recovery experiments. The rolling recovery of drilling fluid is tested at $80^{\circ} \mathrm{C}$ and $150^{\circ} \mathrm{C}$ respectively, where $150^{\circ} \mathrm{C}$ is the actual simulated bottom hole temperature. The experiment is compared with the rolling recovery of water at $80^{\circ} \mathrm{C}$, and the results are shown in Figure 8 .

Recovery rate in drilling fluid Recovery rate in drilling fluid
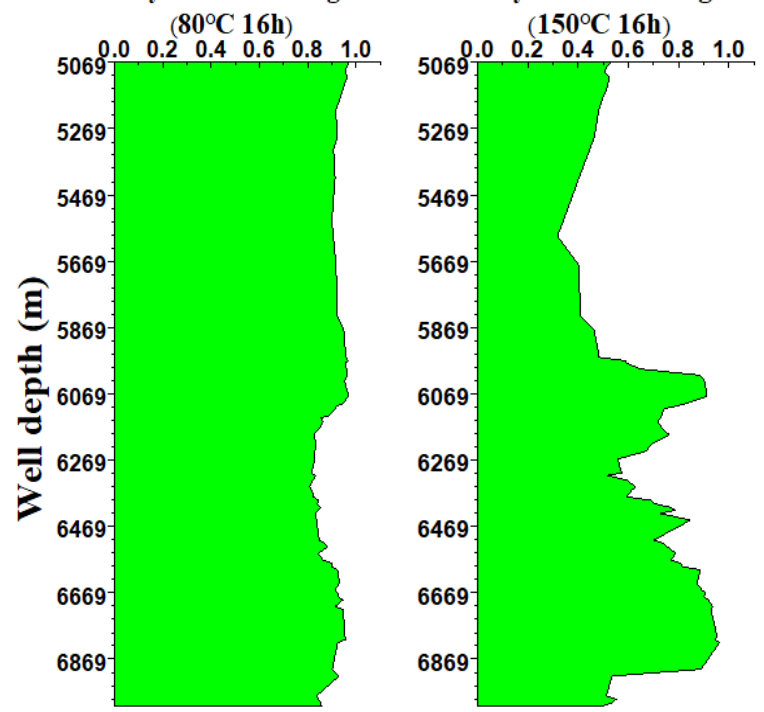

Fig. 8. Recovery rate in drilling fluid of YSA-1 well.

The result shows that the recovery rate is above $80 \%$ at $80^{\circ} \mathrm{C}$, the drilling fluid has good inhibition, reduces the hydration and dispersion ability of the formation, and basically meets the requirements of the formation. However, under the high temperature condition of $150^{\circ} \mathrm{C}$, the recovery rate of drilling fluid fluctuates greatly, and the performance of drilling fluid decreases, and the recovery rate of some well sections drops below $50 \%$.
Therefore, drilling fluid should be further optimized to prevent the occurrence of wellbore instability.

\subsection{Research on inhibition and plugging optimization of drilling fluid}

Paraffin nano-emulsion can improve the compactness of mud cake, reduce the thickness of mud cake and improve the lubricity of drilling fluid. By introducing paraffin nano-emulsion, the inhibition and plugging performance of drilling fluid can be optimized. The mechanism of action of paraffin nano-emulsion includes forming oil film, preventing liquid invasion and inhibiting clay migration. It can realize deformation extrusion and particle size matching to make the plugging more effective. Paraffin nano-emulsion is easy to backflow, and there is no risk of emulsion clogging [12-14].

On the basis of YSA-1 field drilling fluid, $1 \%$ paraffin nano-emulsion is introduced, and the particle size of the paraffin nano-emulsion is mainly about $10 \mathrm{~nm}$ (Fig. 9). After the addition of paraffin nano-emulsion, the drilling fluid properties is shown in Table 3, and the particle size distribution is shown in Fig. 10.

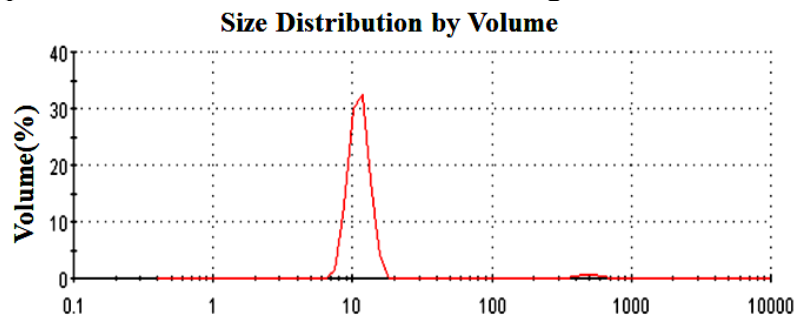

Fig. 9. Particle size distribution of paraffin nano-emulsion.

Table 3. Drilling fluid properties after adding paraffin nano-emulsion.

\begin{tabular}{|c|c|c|c|c|c|c|}
\hline formula & $\begin{array}{c}\text { Density } \\
\left(\mathrm{g} / \mathrm{cm}^{3}\right)\end{array}$ & $\begin{array}{c}\text { Apparent } \\
\text { viscosity } \\
(\mathrm{MPa} \cdot \mathrm{s})\end{array}$ & $\begin{array}{c}\text { Plastic } \\
\text { viscosity } \\
(\mathrm{MPa} \cdot \mathrm{s})\end{array}$ & $\begin{array}{c}\text { Yielding } \\
\text { degree }(\mathrm{pa})\end{array}$ & $\begin{array}{c}\text { Shearing force } \\
(\mathrm{pa})\end{array}$ & $\begin{array}{c}\text { HTHP water } \\
\text { loss } \\
(\mathrm{mL})\end{array}$ \\
\hline $\begin{array}{c}\text { Field drilling } \\
\text { fluid }+1 \% \\
\text { paraffin nano- } \\
\text { emulsion }\end{array}$ & 2.0 & 45.5 & 35 & 10.5 & $4 / 38$ & 3.5 \\
\hline
\end{tabular}




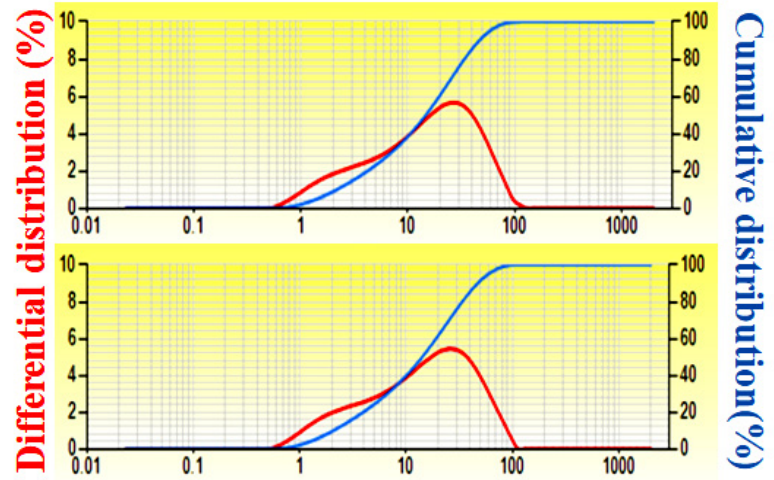

Fig. 10. Particle size distribution of drilling fluid before and after addition paraffin nano-emulsion.

After adding paraffin nano-emulsion, the water loss at $150^{\circ} \mathrm{C}$ is reduced by $1.3 \mathrm{~mL}$, the filtration loss is reduced by about $30 \%$, and the filtration performance of drilling fluid is enhanced. The micro and nano solid particles in paraffin nano-emulsion entering the pore throat can be filled and compacted step by step to form a dense plugging layer and enhance the plugging effect. As shown in Fig. 10, the particle size of the optimized drilling fluid with paraffin nano-emulsion do not change much, so the pressure transfer experiment is used for evaluation. The results show that with the addition of paraffin nano-emulsion, the pressure difference between upstream and downstream becomes larger after the pressure transfer is stable, and the penetration time increases, so the plugging effect is significantly improved. The introduction of paraffin nano-emulsion into KCL-polysulfonate drilling fluid system improves the suppression and plugging performance of drilling fluid and improves the adaptability of drilling fluid to complex formation in Yingsha block.

\section{Conclusion}

(1) The complex well conditions in Yingsha block include lost circulation, sticking of drill tools, drilling blocked and overflow, among which lost circulation and sticking of drill tools are the main forms. The well loss ranges from the Atushi Formation in the upper strata to the Aertash Formation in the lower strata, and the lithology ranges from mudstone, sand-mudstone interbeds to gypsum rock.

(2) In Yingsha area, fractures and micro-fractures have been developed in the lower strata of wells. Quartz and clay minerals are dominant in many formation, and smectite is not contained in the clay minerals. The highest proportion of illite/smectite formation is $25 \%$, the highest expansion rate is $23.87 \%$, and the lowest recovery rate is $3 \%$, showing strong hydration and dispersion characteristics.

(3) The wellbore instability in Yingsha block is mainly due to the good physical properties of sandstone, the development of fractures in the lower strata and the fragmentation of strata. In addition, the lower strata have strong hydration and dispersion ability, which further weakens the rock strength and leads to fractures expansion.
(4) The KCL-Polysulfonate drilling fluid system is adopted in Yingsha block, which has good adaptability to the formation of Yingsha block. The rolling recovery rate of drilling fluid at $80^{\circ} \mathrm{C}$ is more than $80 \%$, but the performance of drilling fluid decreases under high temperature conditions. Introducing paraffin nanoemulsion into KCL-Polysulfonate drilling fluid system can further improve the inhibition and plugging performance of drilling fluid.

\section{Acknowledgments}

This work was financially supported by Tarim Oilfield Project "Study on Formation Characteristics and Technical Countermeasures of Drilling Fluid in Yingsha and Yulong Blocks" (Project No.201019121044) and National Natural Science Foundation of China (ZX20200280).

\section{References}

1. Li L, He H, Fan T, Liu H, Yang T, Wan L, Huang F, Li Z. China Petroleum Exploration, 25,01:1-10(2020)

2. Guo Q, Wu N, Yan W, Chen N. Evaluation method of deep natural gas resources [J]. Acta Petrolei Sinica,40,4:383-394,(2019)

3. Liu H, Liu J, Liu H, Qiu J, Cai B, Liu J, Yang Z, Liu Y. Oil and Gas Reservoirs in Tarim Basin [J]. Natural Gas Industry, 40, 11:76-88,(2020)

4. Sun L, Zou C, Zhu R, Zhang Y, Zhang S, Zhang B, Zhu G, Gao Z. Formation, distribution and potential of deep oil and gas in China [J]. Petroleum Exploration and Development, 40,06:641-649,(2013)

5. Guoqi W, Jun L, Caiyuan D, Xinfeng N, Jianping Y, Ronghu Z, Guangren M, Guangyou Z. Petroleum Exploration and Development in Tarim Basin [A]. Natural Gas Specialized Committee of China Petroleum Institute. The 31st National Natural Gas Academic Conference [C]. Natural Gas Specialized Committee of China Petroleum Society: Natural Gas Specialized Committee of China Petroleum Society,8 (2019)

6. Sun L, Zhou X, Wang G. New progress of petroleum geology and main exploration direction in Tarim Basin [J]. Chinese Journal of Geology, 02, 167-178,(2005)

7. He D, Li D, He J, Wu X. Geological Characteristics and Exploration Implications of the Kuqa Depression and Southwest Depression in Tarim Basin [J]. Acta Petrolei Sinica, 34, 02:201218,(2013)

8. KANG Y. Petroleum resource potential and exploration direction in Tarim Basin [J]. Petroleum Science Bulletin, 3,04:369-375,(2018)

9. Wang L, Wang J, Feng J, Chen L, Shen Q. Petroleum Drilling Techniques, 40,03:73-77,(2012)

10. Wang Q, Li Y. Application of high-temperature resistant $\mathrm{KCl}$ poly-sulfonate drilling fluid system in 
FX well in Iran [J]. Oil Drilling \& Production Technology, 34,01:50-53,(2012)

11. Yu D, Xu H, Wu X, Chen Y, Xu J. Petroleum Drilling Techniques, 48,05:49-54. (2012)

12. Chen J, Wang X, Gao Y, Zhang J. Application of paraffin nanoemulsion drilling fluid technology in horizontal well [J]. Drilling Fluid \& Completion Fluid, 27,04:87-89+102,(2010)

13. Lan Q,Li G, Zhang J, He Xi, Liu B. Influence factors of performance of paraffin nanoemulsion and preparation by low-energy emulsification method [J]. Petroleum Drilling Techniques,40, 01:58-63,(2012)

14. Ye Y, Sheng Y, Zhang Q, et al. Plugging Performance Evaluation of Nanoemulsion in Ultrafine Drilling and Completion Fluid by Pressure Conduction Method[J]. IOP Conference Series: Earth and Environmental Science, 603(2020) 